\title{
Víctima subyacente y víctima por ofensa
}

\section{Underlying victim and victim by offense}

AUTOR: Francisco Javier Camacho Murillo

SUMARIO: I. Definición de Víctima, II. Normativa Aplicable Tratándose de la Víctima, III. Importancia de Ampliar el Catálogo de Víctimas, IV. Propuestas, V. Conclusiones

Resumen: La inserción del Sistema Jurídico Mexicano de los Derechos Humanos trae aparejado el compromiso de armonizar las leyes locales con los diversos instrumentos internacionales dictados en esa materia. No obstante, pese al esfuerzo legislativo en el tema de las víctimas de un delito, las normas mexicanas se han quedado cortas en cuanto al espectro que comprende dicha figura jurídica. Dentro de la investigación realizada se ha comprobado que la norma no ha considerado como víctimas a las personas inculpadas pero absueltas en procesos jurisdiccionales donde el ofendido es el Estado. También se comprobó que hay víctimas que sin ser ofendido o inculpado, sufren las consecuencias derivadas de esos procesos judiciales. Estas omisiones traen como consecuencia que esas víctimas definidas en el presente artículo como subyacente y por ofensa, vean lesionada su esfera jurídica y sean atropelladas en sus derechos.
Abstract: The inclusion of the Mexican Judicial System of Human Rights entails the commitment to harmonize local laws with several international tools related to the subject. $\mathrm{Ne}$ vertheless, despite the legislative effort in the subject of victims of a crime, the Mexican norms have fallen short in regards to the spectrum that encompasses such judicial figure. In this research, it has been proved that the norm has not considered as victims to those people that were accused but absolved in jurisdictional processes where the State was the Offended. Also, it was proven that there are victims that, despite not being offended or accused, are suffering the consequences of those jurisdictional processes. These omissions have caused that those victims, defined in this article as underlying and by offense, find their legal sphere damaged and their rights crushed.

\section{Definición de víctima}

La palabra víctima proviene del latín "víctima", "(Del lat. víctima). 1. f. Persona o animal sacrificado o destinado al sacrificio.2. f. Persona que se expone u ofrece a un grave riesgo en obsequio de otra. 3. f. Persona que padece daño por culpa ajena o por causa fortuita. 4. f. Persona que muere por culpa ajena o por accidente fortuito"1 
Por su parte, Luís Rodríguez Manzanera dice que "se designa a la persona o animal sacrificado o que se destina al sacrificio"2, estas definiciones se toman en sentido lato y sobretodo en referencia a su sentido natural de la palabra.

Siguiendo con el origen de la palabra víctima encontramos al autor Elías Neuman ${ }^{3}$ que atribuye el vocablo víctima "a dos variedades "vincire", animales que se sacrifican a los dioses y deidades, o bien "vincere", que representa al sujeto vencido y así "victimi", en inglés, "victime", en francés y "vittima", en italiano". En estos casos la víctima es ofrecida a los dioses en cumplimiento a cierta promesa por lo regular de tipo religioso y no importaba si era hombre o animal.

Es importante para todos los juristas y estudiosos del derecho, tener un concepto claro de lo que significa el concepto víctima desde el punto de vista jurídico, de ahí que algunos autores hayan escrito en cuanto al contenido de este concepto, por ejemplo para "Israel Kraphin, la palabra "víctima" tiene dos significados distintos; por una parte, se refiere al ser vivo sacrificado a una deidad en cumplimiento de un mito religioso o dedicado como ofrenda a algún poder sobrenatural, por otra, la misma palabra se relaciona con la persona que sufre o es lesionada por otra que actúa movida por una gran variedad de motivos o circunstancias." "En este concepto nos interesa la segunda

${ }^{1}$ CHAMPO SÁNCHEZ Nimrod Mihael en la obra Estudios en homenaje a la maestra Emma Mendoza Bremauntz Entre libertad y castigo: Dilemas del Estado contemporáneo p. 237, http://biblio.juridicas. unam.mx/libros/7/3104/13.pdf, consultado por última vez el 27 de abril de 2015.

Corroborada la cita en el Diccionario de la Real Academia de la Lengua Española. http://lema.rae.es/ drae/?val=V\%C3\%8DCTIMA consultado por última vez el 27 de abril de 2015.

${ }^{2}$ RODRÍGUEZ MANZANERA, Luís. Victimología, Séptima Edición. Editorial Porrúa. México. 2002. Citado por CHAMPO SÁNCHEZ Nimrod Mihael en la obra Estudios en homenaje a la maestra Emma Mendoza Bremauntz Entre libertad y castigo: Dilemas del Estado contemporáneo p. 237, http://biblio.juridicas. unam.mx/libros/7/3104/13.pdf, consultado por última vez el 27 de abril de 2015.

Corroborada la cita en http://www.academia.edu/5879431/Victimologia-Luis-Rodriguez-Manzanera consultado por última vez el 27 de abril de 2015.

${ }^{3} \mathrm{NEUMAN}$, Elias. Victimología. El rol de la víctima en los delitos convencionales y no convencionales, 3a Edición ampliada, Editorial Universidad Argentina, Buenos Aires, 2001. p. 24. Citado por CHAMPO SÁNCHEZ Nimrod Mihael en la obra Estudios en homenaje a la maestra Emma Mendoza Bremauntz Entre libertad y castigo: Dilemas del Estado contemporáneo p. 238, http://biblio.juridicas.unam.mx/ libros/7/3104/13.pdf, consultado por última vez el 27 de abril de 2015.

${ }^{4}$ Citado por CHAMPO SÁNCHEZ Nimrod Mihael en la obra Estudios en homenaje a la maestra Emma Mendoza Bremauntz Entre libertad y castigo: Dilemas del Estado contemporáneo p. 238, http://biblio. juridicas.unam.mx/libros/7/3104/13.pdf, consultado por última vez el 27 de abril de 2015.

Corroborada la cita en http://www.juridicas.unam.mx/publica/rev/boletin/cont/82/art/art4.htm consultado por última vez el 27 de abril de 2015 
parte que se refiere a la persona que sufre una lesión inferida por otra que tuvo alguna circunstancia que lo orilló a cometer un acto que lesiona a otro individuo.

No obstante la definición anterior y tal y como veremos más adelante, la víctima no solo es el sujeto pasivo del delito, sino todo aquel que sufre las consecuencias de la comisión de un hecho delictivo. Como afirma Luis Rodríguez Manzanera, "la víctima no coincide por fuerza con el sujeto pasivo del delito considerado por los juristas, ya que para la victimología, víctima es todo aquel sujeto que sufre por la comisión de una conducta antisocial aunque no sea detentador el derecho vulnerado". ${ }^{5}$

\section{Normativa aplicable tratándose de la víctima}

Dentro del ámbito internacional, el concepto de víctima lleva implícito la lesión de los derechos de las personas por un acto externo atribuible a otra u otras personas y que esa lesión ocasiona daños de tal magnitud, que no basta con la sanción del infractor sino la procuración de la reparación del derecho violentado.

Así, la víctima no solo sufre el perjuicio ocasionado por el delincuente sino también por la omisión o negligencia del encargado de la procuración de justicia. Pero también sucede que el presunto infractor demuestre su inocencia o no se compruebe su culpabilidad y de manera expresa pasa a ser una víctima más del sistema penal. Y aún más, se da el caso de que una persona en primera instancia no figura dentro del nexo causal del infractor y la persona agraviada con la conducta infractora pero que, derivado de esa acción perniciosa también se le perjudica en sus derechos.

\section{A) Declaración sobre los principios fundamentales de justicia para las víctimas de delitos y del abuso de poder.}

Dentro de la normativa internacional, la "Declaración sobre los principios fundamentales de justicia para las víctimas de delitos y del abu-

\footnotetext{
${ }^{5}$ Rodríguez Manzanera, L., Revista Mexicana de Justicia, núm. 2, vol. II, 1984. Citado por FERNANDEZ PÉREZ Rafael en la obra Protección de Derechos de las Víctimas p. 113, http://biblio.juridicas.unam. mx/revista/pdf/DerechoComparado/82/art/art4.pdf, Consultado por última vez el 27 de abril de 2015.
} 
so de poder" adoptada por la Asamblea General de la Organización de las Naciones Unidas en la Resolución 40/34 del 29 de noviembre de $1985^{6}$, se sentaron las bases de lo que debía de considerarse como víctimas y los casos en que una persona común se convertía en tal. De igual forma, se determinan los derechos mínimos de las víctimas para tratar de restaurar sus derechos lesionados.

Este instrumento jurídico internacional en el apartado A párrafos primero y segundo, define como víctimas a:

"A. Las víctimas de delitos 1. Se entenderá por "víctimas" las personas que, individual o colectivamente, hayan sufrido daños, inclusive lesiones físicas o mentales, sufrimiento emocional, pérdida financiera o menoscabo sustancial de los derechos fundamentales, como consecuencia de acciones u omisiones que violen la legislación penal vigente en los Estados Miembros, incluida la que proscribe el abuso de poder. 2. Podrá considerarse "víctima" a una persona, con arreglo a la presente Declaración, independientemente de que se identifique, aprehenda, enjuicie o condene al perpetrador e independientemente de la relación familiar entre el perpetrador y la víctima. En la expresión "víctima" se incluye además, en su caso, a los familiares o personas a cargo que tengan relación inmediata con la víctima directa y a las personas que hayan sufrido daños al intervenir para asistir a la víctima en peligro o para prevenir la victimización."

De una lectura ligera de las definiciones anotadas, conviene distinguir los siguientes elementos:

a) Puede tratarse de una sola persona o varias con la condición de que hayan sufrido daños con motivo de la acción u omisión que violen la legislación penal.

b) El espectro de los daños no se refiere solo en el caso de que sean lesiones físicas sino que abarca daño mental, emocional, financiero y el que se refiera a los derechos fundamentales.

c) Debe existir una legislación penal que defina y castigue la conducta infractora y evidentemente, que contemple al perjudicado. En otras palabras, debe definir quién es el sujeto activo en la comisión de un ilícito, en qué consiste el ilícito, quien es el sujeto pasivo (víctima)

${ }^{6} \mathrm{http}: / /$ www.ordenjuridico.gob.mx/TratInt/Derechos\%20Humanos/INST\%2028.pdf consultada por última vez el 27 de abril de 2015. 
que ha sufrido la acción perniciosa del pasivo y que se acredite la culpabilidad.

d) La calidad de víctima no se pierde aún cuando el sujeto activo sea castigado por su conducta ilícita.

e) No es limitante para considerar como víctima el parentesco, sea consanguíneo o por afinidad.

f) Define como víctimas indirectas a las personas que sufran cualquiera de los daños apuntados con motivo de un nexo familiar o civil con la víctima directa (sujeto pasivo).

g) Considera además como víctimas indirectas a cualquier persona que hayan sufrido cualquiera de los daños referidos con motivo de su intervención y asistencia la víctima directa o para prevenir la victimización.

De la misma manera, en el apartado A párrafos $4,6,8,10,12,14$, 15 y 17, de la declaración de la Organización de las Naciones Unidas que nos ocupa, determina como derechos mínimos de las víctimas lo siguiente:

"Acceso a la justicia y trato justo. 4. Las víctimas serán tratadas con compasión y respeto por su dignidad. Tendrán derecho al acceso a los mecanismos de la justicia y a una pronta reparación del daño que hayan sufrido, según lo dispuesto en la legislación nacional. 6. Se facilitará la adecuación de los procedimientos judiciales y administrativos a las necesidades de las víctimas: a) Informando a las víctimas de su papel y del alcance, el desarrollo cronológico y la marcha de las actuaciones, así como de la decisión de sus causas, especialmente cuando se trate de delitos graves y cuando hayan solicitado esa información; b) Permitiendo que las opiniones y preocupaciones de las víctimas sean presentadas y examinadas en etapas apropiadas de las actuaciones siempre que estén en juego sus intereses, sin perjuicio del acusado y de acuerdo con el sistema nacional de justicia penal correspondiente; c) Prestando asistencia apropiada a las víctimas durante todo el proceso judicial; d) Adoptando medidas para minimizar las molestias causadas a las víctimas, proteger su intimidad, en caso necesario, y garantizar su seguridad, así como la de sus familiares y la de los testigos en su favor, contra todo acto de intimidación y represalia; e) Evitando demoras innecesarias en la resolución de las causas y en la ejecución de los mandamientos o decretos que concedan indemnizaciones a las víctimas."

"Resarcimiento. 8. Los delincuentes o los terceros responsables de su conducta resarcirán equitativamente, cuando proceda, a las víctimas, sus familiares o las personas a su cargo. Ese resarcimiento comprenderá la devolución de los bienes o el pago por los daños o pérdidas sufridos, el reembolso de los gastos realizados como consecuencia de la victimización, la prestación de servicios y la restitución de derechos. 10. En los casos en que se causen daños considerables al medio ambiente, el resarcimiento que se exija comprenderá, en la medida de lo posible, la rehabilitación del medio ambiente, la reconstrucción de la infraestructura, la reposición de las instalaciones comunitarias y el reembolso de los gastos de reubicación cuando esos daños causen la disgregación de una comunidad."

"Indemnización. 12. Cuando no sea suficiente la indemnización procedente del delincuente o de otras fuentes, los Estados procurarán indemnizar financieramente: a) A las víctimas 
de delitos que hayan sufrido importantes lesiones corporales o menoscabo de su salud física o mental como consecuencia de delitos graves; b) A la familia, en particular a las personas a cargo, de las víctimas que hayan muerto o hayan quedado física o mentalmente incapacitadas como consecuencia de la victimización."

"Asistencia. 14. Las víctimas recibirán la asistencia material, médica, psicológica y social que sea necesaria, por conducto de los medios gubernamentales, voluntarios, comunitarios y autóctonos. 15. Se informará a las víctimas de la disponibilidad de servicios sanitarios y sociales y demás asistencia pertinente, y se facilitará su acceso a ellos. 16. Se proporcionará al personal de policía, de justicia, de salud, de servicios sociales y demás personal interesado capacitación que lo haga receptivo a las necesidades de las víctimas y directrices que garanticen una ayuda apropiada y rápida. 17. Al proporcionar servicios y asistencia a las víctimas, se prestará atención a las que tengan necesidades especiales por la índole de los daños sufridos o debido a factores como los mencionados en el párrafo 3 supra."

\section{- Acceso a la justicia y trato justo}

Destaca el trato que deben recibir las víctimas, que existan mecanismos de procuración e impartición de justicia expedita, asistencia durante los procesos y minimizar la molestia a las víctimas, así como la reparación del daño.

\section{- Resarcimiento}

Define el alcance del resarcimiento de las víctimas a cargo de los delincuentes o terceros responsables pero no estima una penalización adicional por haber producido el estado de víctima.

\section{- Indemnización}

No basta con el resarcimiento, sino la indemnización financiera subsidiaria por parte del Estado en los casos de que la víctima haya sufrido lesiones corporales o deterioro en su salud física y mental. Igualmente procederá la indemnización financiera a cargo del Estado y a favor de los familiares y personas a cargo, cuando la víctima directa muera o quede incapacitada física o mentalmente.

No alcanza cuando el deterioro o incapacidad física o mental, sea sufrida por los familiares y personas a cargo de la víctima directa.

\section{- Asistencia}

Considera como acreedor de este derecho al Estado. Comprende el ámbito material, médico, psicológico y social. Incluye la información a las víctimas de los servicios sanitarios y sociales facilitando el acceso de los mismos.

Esta asistencia tendrá que ser especial o especializada de acuerdo a los daños sufridos o cuando se requiera en razón de sexo, edad, 
idioma, religión, nacionalidad creencias o prácticas culturales, situación económica, nacimiento o situación familiar, origen étnico o social, o impedimento físico.

Sin embrago, este derecho se queda corto pues limita la asistencia a medios gubernamentales, voluntarios, comunitarios y autóctonos, dejando de lado la posibilidad del pago de la asistencia por parte de particulares.

Así mismo, define en el apartado B "Las víctimas del abuso de poder" párrafos 18 y 19:

"18. Se entenderá por "víctimas" las personas que, individual o colectivamente, hayan sufrido daños, inclusive lesiones físicas o mentales, sufrimiento emocional, pérdida financiera o menoscabo sustancial de sus derechos fundamentales, como consecuencia de acciones u omisiones que no lleguen a constituir violaciones del derecho penal nacional, pero violen normas internacionalmente reconocidas relativas a los derechos humanos.

19. Los Estados considerarán la posibilidad de incorporar a la legislación nacional normas que proscriban los abusos de poder y proporcionen remedios a las víctimas de esos abusos. En particular, esos remedios incluirán el resarcimiento y la indemnización, así como la asistencia y el apoyo materiales, médicos, psicológicos y sociales necesarios."

Resalta el hecho de que los estados signantes reconozcan que dentro de su ejercicio, el Estado sea el perpetrador de conductas delictivas y la necesidad de dotar dentro de su marco jurídico, la asistencia, el resarcimiento y la indemnización a favor de las víctimas.

\section{- Convención Americana sobre Derechos Humanos, adoptada en San José de Costa Rica}

El 07 de mayo de $1981^{7}$ mediante publicación en el Diario Oficial de la Federación el Estado Mexicano adoptó los acuerdos celebrados en la Convención Americana sobre Derechos Humanos, adoptada en San José de Costa Rica.

- Derechos Humanos y preservación de los mismos

En una primera parte, se obliga a los Estados participante a respetar los derechos consignados en dicho instrumento jurídico así como a la creación o adecuación de su marco jurídico para preservar los

\footnotetext{
${ }^{7}$ http://www.dof.gob.mx/nota_detalle.php?codigo=4645612\&fecha=07/05/1981 consultado por última vez el 27 de abril de 2015
} 
derechos y libertades en aquel consignado, tal y como refieren los artículos $1^{\circ}$ y $2^{\circ}$ :

"Artículo 1. Obligación de Respetar los Derechos

1. Los Estados Partes en esta Convención se comprometen a respetar los derechos y libertades reconocidos en ella y a garantizar su libre y pleno ejercicio a toda persona que esté sujeta a su jurisdicción, sin discriminación alguna por motivos de raza, color, sexo, idioma, religión, opiniones políticas o de cualquier otra índole, origen nacional o social, posición económica, nacimiento o cualquier otra condición social.

2. Para los efectos de esta Convención, persona es todo ser humano.

Artículo 2. Deber de Adoptar Disposiciones de Derecho Interno

Si el ejercicio de los derechos y libertades mencionados en el Artículo 1 no estuviere ya garantizado por disposiciones legislativas o de otro carácter, los Estados Partes se comprometen a adoptar, con arreglo a sus procedimientos constitucionales y a las disposiciones de esta convención, las medidas legislativas o de otro carácter que fueren necesarias para hacer efectivos tales derechos y libertades."

- La honra y la dignidad como valor supremo de las personas. Si bien no de forma expresa, se reconoce la posibilidad de que una persona sea violentada en su derecho a la honra y a la dignidad con motivo de la comisión de un ilícito. Lo anterior conforme al artículo 11:

"Artículo 11. Protección de la Honra y de la Dignidad

1. Toda persona tiene derecho al respeto de su honra y al reconocimiento de su dignidad.

2. Nadie puede ser objeto de ingerencias (sic) arbitrarias o abusivas en su vida privada, en la de su familia, en su domicilio o en su correspondencia, ni de ataques ilegales a su honra o reputación.

3. Toda persona tiene derecho a la protección de la ley contra esas ingerencias (sic) o esos ataques."

\section{- Presunción de inocencia.}

En su artículo 8 párrafo 2 establece como una garantía judicial de las personas, la presunción de inocencia hasta que no se establezca legalmente su culpabilidad:

"Artículo 8. Garantías Judiciales 2. Toda persona inculpada de delito tiene derecho a que se presuma su inocencia mientras no se establezca legalmente su culpabilidad. Durante el proceso, toda persona tiene derecho, en plena igualdad, a las siguientes garantías mínimas:

a) derecho del inculpado de ser asistido gratuitamente por el traductor o intérprete, si no comprende o no habla el idioma del juzgado o tribunal;

b) comunicación previa y detallada al inculpado de la acusación formulada;

c) concesión al inculpado del tiempo y de los medios adecuados para la preparación de su defensa;

d) derecho del inculpado de defenderse personalmente o de ser asistido por un defensor de su elección o de comunicarse libre y privadamente con su defensor; 
e) derecho irrenunciable de ser asistido por un defensor proporcionado por el Estado, remunerado o no según la legislación interna, si el inculpado no se defendiere por sí mismo ni nombrare defensor dentro del plazo establecido por la ley;

f) derecho de la defensa de interrogar a los testigos presentes en el tribunal y de obtener la comparecencia, como testigos o peritos, de otras personas que puedan arrojar luz sobre los hechos;

g) derecho a no ser obligado a declarar contra sí mismo ni a declararse culpable, y

h) derecho de recurrir del fallo ante juez o tribunal superior"

Este instrumento internacional es de vital trascendencia porque de manera pertinente considera que no siempre la persona señalada como sujeto pasivo es culpable de los delitos imputados. Tan es así, que dispone una serie de garantías judiciales a favor del inculpado a fin de preservar la presunción de inocencia.

\section{B) En México}

Si bien es cierto que en nuestro país hubo algunos esfuerzos legislativos como la Ley Sobre Auxilio a las Víctimas del Delito del Estado de México, no es hasta 1993 cuando la Constitución Política de los Estados Unidos Mexicanos reconoce los derechos de las víctimas del delito; posteriormente, mediante reformas de 1996, 2000 y 2008, se han ido perfeccionando los derechos de las víctimas.

Actualmente, nuestra carta magna establece en el apartado $\mathrm{C}$ del artículo 20:

"Artículo 20. El proceso penal será acusatorio y oral. Se regirá por los principios de publicidad, contradicción, concentración, continuidad e inmediación.

$\cdots$

C. De los derechos de la víctima o del ofendido:

I. Recibir asesoría jurídica; ser informado de los derechos que en su favor establece la Constitución y, cuando lo solicite, ser informado del desarrollo del procedimiento penal;

II. Coadyuvar con el Ministerio Público; a que se le reciban todos los datos o elementos de prueba con los que cuente, tanto en la investigación como en el proceso, a que se desahoguen las diligencias correspondientes, y a intervenir en el juicio e interponer los recursos en los términos que prevea la ley. Cuando el Ministerio Público considere que no es necesario el desahogo de la diligencia, deberá fundar y motivar su negativa;

III. Recibir, desde la comisión del delito, atención médica y psicológica de urgencia;

IV. Que se le repare el daño. En los casos en que sea procedente, el Ministerio Público estará obligado a solicitar la reparación del daño, sin menoscabo de que la víctima u ofendido lo pueda solicitar directamente, y el juzgador no podrá absolver al sentenciado de dicha reparación si ha emitido una sentencia condenatoria. La ley fijará procedimientos ágiles para ejecutar las sentencias en materia de reparación del daño;

V. Al resguardo de su identidad y otros datos personales en los siguientes casos: cuando sean menores de edad; cuando se trate de delitos de violación, trata de personas, secuestro o delincuencia organizada; y cuando a juicio del juzgador sea necesario para su protección, salvaguardando en todo caso los derechos de la defensa. El Ministerio Público deberá ga- 
rantizar la protección de víctimas, ofendidos, testigos y en general todas los sujetos que intervengan en el proceso. Los jueces deberán vigilar el buen cumplimiento de esta obligación;

VI. Solicitar las medidas cautelares y providencias necesarias para la protección y restitución de sus derechos, $y$

VII. Impugnar ante autoridad judicial las omisiones del Ministerio Público en la investigación de los delitos, así como las resoluciones de reserva, no ejercicio, desistimiento de la acción penal o suspensión del procedimiento cuando no esté satisfecha la reparación del daño."

Así mismo, en los párrafos décimo cuarto del artículo 16, segundo del artículo 19 y fracción $\mathrm{V}$ apartado $\mathrm{B}$ del artículo 20, todos de la misma Constitución Política de los Estados Unidos Mexicanos, se complementa el marco normativo relativo a las víctimas:

"Artículo 16. ...

Los Poderes Judiciales contarán con jueces de control que resolverán, en forma inmediata, y por cualquier medio, las solicitudes de medidas cautelares, providencias precautorias y técnicas de investigación de la autoridad, que requieran control judicial, garantizando los derechos de los indiciados y de las víctimas u ofendidos. Deberá existir un registro fehaciente de todas las comunicaciones entre jueces y Ministerio Público y demás autoridades competentes.

\section{Artículo 19....}

El Ministerio Público sólo podrá solicitar al juez la prisión preventiva cuando otras medidas cautelares no sean suficientes para garantizar la comparecencia del imputado en el juicio, el desarrollo de la investigación, la protección de la víctima, de los testigos o de la comunidad, así como cuando el imputado esté siendo procesado o haya sido sentenciado previamente por la comisión de un delito doloso. El juez ordenará la prisión preventiva, oficiosamente, en los casos de delincuencia organizada, homicidio doloso, violación, secuestro, trata de personas, delitos cometidos con medios violentos como armas y explosivos, así como delitos graves que determine la ley en contra de la seguridad de la nación, el libre desarrollo de la personalidad y de la salud.

Artículo 20. ...

B. ...

I. A que se presuma su inocencia mientras no se declare su responsabilidad mediante sentencia emitida por el juez de la causa.

...

V. Será juzgado en audiencia pública por un juez o tribunal. La publicidad sólo podrá restringirse en los casos de excepción que determine la ley, por razones de seguridad nacional, seguridad pública, protección de las víctimas, testigos y menores, cuando se ponga en riesgo la revelación de datos legalmente protegidos, o cuando el tribunal estime que existen razones fundadas para justificarlo.

Como se ha podido apreciar, las consideraciones establecidas en la Constitución Federal, han recogido los principios y máximas señaladas en los instrumentos internacionales invocados con una pequeña salvedad: no define quien o quienes se considerarán como víctimas. 
En delincuencia organizada, las actuaciones realizadas en la fase de investigación podrán tener valor probatorio, cuando no puedan ser reproducidas en juicio o exista riesgo para testigos o víctimas. Lo anterior sin perjuicio del derecho del inculpado de objetarlas o impugnarlas y aportar pruebas en contra;

Como se puede apreciar, existe casi una total concordancia entre la normativa internacional invocada en el presente trabajo (acceso a la justicia, presunción de inocencia, asistencia, reparación del daño, indemnización) salvo porque nuestra carta magna no define quien es o que características reúne la víctima.

Ahora bien, el 09 de enero de 2013 se publicó en el Diario Oficial de la Federación ${ }^{8}$ la "Ley General de Víctimas" y que en la parte que interesa al presente trabajo, hace una definición de lo que se va a considerar como víctima:

"Artículo 4. Se denominarán víctimas directas aquellas personas físicas que hayan sufrido algún daño o menoscabo económico, físico, mental, emocional, o en general cualquiera puesta en peligro o lesión a sus bienes jurídicos o derechos como consecuencia de la comisión de un delito o violaciones a sus derechos humanos reconocidos en la Constitución y en los Tratados Internacionales de los que el Estado Mexicano sea Parte.

Son víctimas indirectas los familiares o aquellas personas físicas a cargo de la víctima directa que tengan una relación inmediata con ella.

Son víctimas potenciales las personas físicas cuya integridad física o derechos peligren por prestar asistencia a la víctima ya sea por impedir o detener la violación de derechos o la comisión de un delito.

La calidad de víctimas se adquiere con la acreditación del daño o menoscabo de los derechos en los términos establecidos en la presente Ley, con independencia de que se identifique, aprehenda, o condene al responsable del daño o de que la víctima participe en algún procedimiento judicial o administrativo.

Son víctimas los grupos, comunidades u organizaciones sociales que hubieran sido afectadas en sus derechos, intereses o bienes jurídicos colectivos como resultado de la comisión de un delito o la violación de derechos."

Igual que como sucedió cuando vimos lo relativo a los instrumentos internacionales, las definiciones de víctimas solamente abarcan:

1) Víctima directa es la persona o grupo de personas que en el proceso penal figuran como ofendidos.

${ }^{8} \mathrm{http}: / /$ www.dof.gob.mx/nota_detalle.php?codigo=5284359\&fecha=09/01/2013 consultado por última vez el 27 de Abril de 2015 
2) Víctima indirecta los familiares o las personas a cargo del ofendido

3) Víctima potencial son las personas que auxilian, impiden o detienen la comisión de un delito o violación de derechos humanos. Personalmente se considera que esta definición huele más a testigos que a víctimas.

\section{Importancia de ampliar el catalogo de víctimas.}

Sentadas las definiciones legales de víctimas limitadas solamente como directas, indirectas y las potenciales, es preciso se amplíe el catalogo de víctimas puesto que la ley vigente:

a) No considera como víctimas a aquellas personas que sufren de manera indebida procedimientos penales en los que la autoridad no acredita los elementos constitutivos de la figura penal.

b) Tampoco se considera víctima a la persona que en un procedimiento penal previo figuró como ofendido pero, por acción u omisión de la autoridad, el sentenciado le causa daños o perjuicios.

c) No se considera como víctima a las personas que sin reunir los atributos de sujeto pasivo o activo en la comisión de un delito, pudieran resultar dañados o perjudicados por un ilícito sin posibilidad de que tengan un resarcimiento satisfactorio.

No se omite poner en la palestra que de las 32 entidades federativas, 25 cuentan con legislación aplicable para la atención de víctimas (a excepción de Coahuila, Querétaro, Quintana Roo, Tabasco, Tlaxcala, Veracruz y Zacatecas) ${ }^{9}$; sin embargo, en ninguna de las entidades que si cuentan con las leyes en comento, se contemplan las figuras jurídicas que en la presente investigación se proponen.

A fin de demostrar lo antes afirmado, veamos los delitos que pudieran configurar las victimas señaladas en los incisos antecedentes.

\section{A) Delitos contra la seguridad de la Nación ${ }^{10}$.}

En los casos de los delitos de Traición a la Patria, Espionaje, Sedi-

\footnotetext{
${ }^{9}$ http://www.cndh.org.mx/node/913947

${ }^{10}$ Libro Segundo, Título Primero, Capítulos I al IV, VII y VIII del Código Penal Federal. http://www. diputados.gob.mx/LeyesBiblio/pdf/9_120315.pdf consultado por última vez el 27 de Abril de 2015
} 
ción, Motín, Rebelión, Terrorismo, Sabotaje y Conspiración, los Estados Unidos Mexicanos son o pueden ser el sujeto pasivo de dichas conductas y que por ende, le corresponde a este hacer las denuncias o querellas correspondientes. Sin embargo, como en cualquier procedimiento penal, es posible que ejercitándose la acción penal, esta no culmine en una sentencia condenatoria por no acreditarse los elementos constitutivos de la figura delictiva.

En este caso, el inculpado tuvo que soportar un procedimiento penal incluso privado de su libertad ocasionándole un menoscabo en sus derechos fundamentales como lo es la presunción de inocencia y sin embargo, al no ser hallado culpable, no tiene a su alcance la posibilidad de exigir un resarcimiento, indemnización o atención profesional por la violación del mencionado derecho humano.

La sujeción al proceso privado de su libertad ocasiona un daño en el honor del inculpado, no restablecido con su absolución.

Todo individuo, al vivir en sociedad, tiene el derecho de ser respetado y considerado y, correlativamente, tiene la obligación de respetar a aquellos que lo rodean. En el campo jurídico esta necesidad se traduce en un derecho que involucra la facultad que tiene cada individuo de pedir que se le trate en forma decorosa y la obligación de los demás de responder a este tratamiento. Por lo general, existen dos formas de sentir y entender el honor: a) en el aspecto subjetivo o ético, el honor se basa en un sentimiento íntimo que se exterioriza por la afirmación que la persona hace de su propia dignidad; y b) en el aspecto objetivo, externo o social, como la estimación interpersonal que la persona tiene por sus cualidades morales y profesionales dentro de la comunidad. En el aspecto subjetivo, el honor es lesionado por todo aquello que lastima el sentimiento de la propia dignidad. En el aspecto objetivo, el honor es lesionado por todo aquello que afecta a la reputación que la persona merece, es decir, el derecho a que otros no condicionen negativamente la opinión que los demás hayan de formarse de nosotros. ${ }^{11}$

\footnotetext{
${ }^{11}$ Tesis con registro electrónico 2000083. http://200.38.163.178/sjfsist/(F(5dNDcC0oMytMU-sSj29gyrcjWbWMcqc1Z_gSWfoYqUWrTHZoaSYLI8_tC5MvotqOSc9ziDI6ur5ia3UFsMdli3h8dq9j221F4_TCcDnwLdYgJGcU6suX8IweL7BTFci6rg89tZmXfh_jUNa9haiOuio5ms98-ASi-RAU2E3TA81))/Paginas/ DetalleGeneralV2.aspx Epoca $=1 \mathrm{e} 3 \mathrm{e} 10000000000 \&$ Apendice $=1000000000000 \&$ Expresion $=200008$ 3\&Dominio=Rubro,Texto\&TA_TJ=2\&Orden=1\&Clase=DetalleTesisBL\&NumTE=1\&Epp=20\&Desde=$100 \&$ Hasta $=-100 \&$ Index $=0 \&$ InstanciasSeleccionadas $=6,1,2,50,7 \& I D=2000083 \&$ Hit $=1 \& \mid D s=2000083 \&$ tipoTesis=\&Semanario=0\&tabla= consultado por última vez el 27 de Abril de 2015.
} 
El antecedente más cercano para que un inculpado pudiera repetir contra de la persona que hubiera formulado la denuncia o querella, lo constituía el delito de "Calumnias" pero que dentro de la evolución respecto a la despenalización de los Delitos contra el Honor y particularmente el delito de "Calumnias" contemplados en el Código Penal Federal, el mismo fue derogado mediante decreto publicado en el Diario Oficial de la Federación el día 13 de Abril de $2007^{12}$.

No se estima prudente considerar que todos los absueltos en procedimientos penales sean considerados como víctimas como acá se plantea puesto que en los casos de que el ofendido es un particular, el absuelto tiene a su alcance la reparación civil correspondiente al daño moral $^{13}$ mismo que debe reclamar en un juicio civil ordinario no obstante el desgaste emocional y económico aún sin la garantía de que obtenga el éxito que espera. Tratándose de los delitos considerados contra la seguridad de la Nación, no cabe la posibilidad de reclamar sufrimiento por daño moral pues el ofendido no es un particular y por ende se considera se surte la improcedencia de ese procedimiento civil.

\section{B) Delitos contra la seguridad pública.}

En los casos del delito de Evasión de Presos ${ }^{14}$ y específicamente tratándose de personas condenadas, es evidente el daño o perjuicio que le puede ocasionar daños y perjuicios desde el ámbito mental y físico sabedor que el delincuente ha quedado libre por acción u omisión de la autoridad competente. En esta hipótesis se debe considerar como víctima a la persona que en el procedimiento penal previo figuró como ofendido pero, por la evasión del sentenciado, éste le ocasione daños o perjuicios al ofendido.

Es verdad que el ofendido previamente ya fue considerado como víctima directa pero ello no es limitante para considerarlo nuevamente como víctima derivado del ilícito referido.

\footnotetext{
${ }^{12} \mathrm{http}: / /$ www.dof.gob.mx/nota_detalle.php?codigo=4975044\&fecha=13/04/2007 consultado por última vez el 27 de abril de 2015

${ }^{13}$ Artículo 1916 párrafos primero, quinto y sexto del Código Civil Federal. http://www.diputados.gob. mx/LeyesBiblio/pdf/2_241213.pdf consultado por última vez el 27 de Abril de 2015

${ }^{14}$ Artículos 150 y 152 del Código Penal Federal.

http://www.diputados.gob.mx/LeyesBiblio/pdf/9_120315.pdf consultado por última vez el 27 de Abril de 2015
} 


\section{C) Delitos cometidos por servidores públicos.}

En los casos de los delitos de Ejercicio Indebido de Servidor Público, Abuso de Autoridad y contra la Administración de Justicia, se puede ocasionar un daño a una persona que no figuró en el acto consecuente y que lo pondría como víctima. Veamos lo que señala el Código Penal Federal respecto de los ilícitos mencionados:

"Artículo 214.- Comete el delito de ejercicio indebido de servicio público, el servidor público que:

$\ldots$

IV.- Por sí o por interpósita persona, sustraiga, destruya, oculte, utilice, o inutilice ilícitamente información o documentación que se encuentre bajo su custodia o a la cual tenga acceso, o de la que tenga conocimiento en virtud de su empleo, cargo o comisión.

VI.- Teniendo obligación por razones de empleo, cargo o comisión, de custodiar, vigilar, proteger o dar seguridad a personas, lugares, instalaciones u objetos, incumpliendo su deber, en cualquier forma propicie daño a las personas, o a los lugares, instalaciones u objetos, o pérdida o sustracción de objetos que se encuentren bajo su cuidado."

En el caso de las dos fracciones insertas, puede suceder el caso de que el funcionario que cometa el lícito, deje de laborar después de perpetuado el mismo y el afectado no tenga oportunidad de denunciarlo de manera oportuna. En este caso queda de manifiesto la afectación de la persona.

"Artículo 215.- Cometen el delito de abuso de autoridad los servidores públicos que incurran en alguna de las conductas siguientes:

I.- Cuando para impedir la ejecución de una ley, decreto o reglamento, el cobro de un impuesto o el cumplimiento de una resolución judicial, pida auxilio a la fuerza pública o la emplee con ese objeto;

...

V. Cuando el encargado o elemento de una fuerza pública, requerido legalmente por una autoridad competente para que le preste auxilio se niegue a dárselo o retrase el mismo injustificadamente. La misma previsión se aplicará tratándose de peritos.

$\ldots$

XI.- Cuando autorice o contrate a quien se encuentre inhabilitado por resolución firme de autoridad competente para desempeñar un empleo, cargo o comisión en el servicio público, siempre que lo haga con conocimiento de tal situación;"

En el supuesto de la fracción I y específicamente se impida la ejecución de una resolución judicial, la parte que le beneficie dicha resolución, se ve afectado por el impedimento. Nótese que no se habla de ofendido o de procedimientos penales, sino de cualquier otro procedimiento jurisdiccional donde se perjudique a la parte que haya obtenido a su favor la resolución judicial. 
Tratándose de la fracción V, es susceptible de considerar cualquier procedimiento jurisdiccional donde la parte promoverte de dicha medida es perjudicada por la inejecución de la orden mencionada.

Y en el caso de la fracción XI, la víctima es quien también haya competido por el empleo, cargo o comisión y no haya conseguido el mismo derivado de la acción irregular del contratante. Nótese que en caso de no considerarlo como víctima, al aspirante solo le quedaría ejercitar una acción laboral cuyo alcance máximo sería que se le asignara el empleo, cargo o comisión pero no tendría chance de resarcimiento o indemnización correspondiente.

"Artículo 225.- Son delitos contra la administración de justicia, cometidos por servidores públicos los siguientes:

III.- Litigar por sí o por interpósita persona, cuando la ley les prohiba el ejercicio de su profesión;

...

VII.- Ejecutar actos o incurrir en omisiones que produzcan un daño o concedan a alguien una ventaja indebidos;"

Siendo el caso de la hipótesis prevista en la fracción III cabe la posibilidad de que la víctima sea cualquiera de las partes intervinientes en un procedimiento jurisdiccional distinto del penal pues el que litiga sin autorización y obtiene resolución favorable de sus intereses o de su representado convierte en victima a su contraparte; también puede suceder que el impedido para litigar pierda el negocio jurídico donde el papel de víctima recaería en su cliente. Si se fija, la conducta no es ocasionada por los litigantes sino por la omisión de la autoridad jurisdiccional.

Igual sucede en el caso de la fracción VII porque la ventaja indebida concedida a cualquiera de las partes transforma al perjudicado en víctima.

Con lo anterior en este apartado, es evidente que no se considera como víctima a las personas que sin reunir los atributos de sujeto pasivo o activo en la comisión de un delito, pudieran resultar dañados o perjudicados por ese ilícito sin posibilidad de que tengan un resarcimiento satisfactorio. 


\section{Propuestas}

A. Se incorpore a la legislación federal y estatal, la figura de víctima subyacente ${ }^{15}$ :

"Se considera víctima subyacente a la persona que en un procedimiento penal iniciado mediante una denuncia o querella formulada por una autoridad, tenga la calidad de inculpado y dicho procedimiento se concluya sin que sea considerado como culpable por el delito que se le acuse, a excepción de que el procedimiento penal sea sobreseído a causa del perdón otorgado por el ofendido."

B. Se incorpore a la legislación federal y estatal, la figura de víctima por ofensa. ${ }^{16}$

"Se considera víctima por ofensa a la persona que sufra un daño o perjuicio, cuando en un procedimiento penal previo haya figurado como ofendido y que la persona hallada culpable en el mismo procedimiento, evada su pena privativa de la libertad de forma temporal o permanentemente.

También se considera víctima por ofensa a la persona que sufra un daño o perjuicio y que sea ajena a los sujetos pasivo y activo que figuren en la comisión de delitos."

\section{Conclusiones}

1. Nuestra Carta Magna así como los convenios internacionales suscritos por México, privilegian el respeto a los derechos humanos.

2. Nuestra Constitución Política respeta de manera inalienable los derechos consagrados cualquier tratado, convención o acuerdo internacional que el Gobierno Federal haya firmado o de los que celebre o forme parte.

\section{Uno de los derechos humanos reconocidos y protegidos por}

\footnotetext{
${ }^{15}$ subyacente. (Del lat. subiācens, -entis). 1. adj. Que subyace. http://lema.rae.es/drae/?val=subyacente 2. intr. Dicho de una cosa: Estar oculta tras otra. http://lema.rae.es/drae/?val=subyace consultado por última vez el 27 de abril de 2015.

${ }^{16} 1$. f. Acción y efecto de ofender. http://lema.rae.es/drae/?val=ofensa ofender. (Del lat. offendĕre). 1. tr. Humillar o herir el amor propio o la dignidad de alguien, o ponerlo en evidencia con palabras o con hechos. 2. tr. Ir en contra de lo que se tiene comúnmente por bueno, correcto o agradable. http:// lema.rae.es/drae/?val=ofender consultado por última vez el 27 de abril de 2015
} 
nuestra legislación es la presunción de inocencia de toda persona mientras no se declare su responsabilidad mediante sentencia emitida por un juez.

4. Diversos documentos internacionales suscritos por nuestro país, imponen como tal la presunción de inocencia en todo momento.

5. De igual forma, nuestra Carta Magna salvaguarda la reparación del daño ocasionado a la víctima u ofendido debiendo contar con jueces de control que garantizarán los derechos de las víctimas u ofendidos.

6. La Constitución Política de los Estados Unidos Mexicanos establece la obligación de todas las autoridades que velen por el respeto a los derechos humanos.

7. La Constitución Política de los Estados Unidos Mexicanos no define quienes son las víctimas.

8. La Ley General de Víctimas solamente considera como víctimas a la directa, indirecta y potencial.

9. Hay víctimas que sufren daños y perjuicios como consecuencia de acciones $u$ omisiones que no lleguen a constituir violaciones del derecho penal nacional, pero violen normas internacionalmente reconocidas relativas a los derechos humanos.

10. Nuestras normas federales en materia de atención a víctimas, son pobres en considerar como tales a las personas que sufren de manera indebida procedimientos penales en los que la autoridad no acredita los elementos constitutivos de la figura penal.

11. La legislación federal no contemplan como víctima a la persona que en un procedimiento penal previo figuró como ofendido pero, por acción u omisión de la autoridad, el sentenciado le causa daños o perjuicios.

12. Las normas federales son ciegas en cuanto al daño que se les pudiera ocasionar a personas que sin reunir los atributos de sujeto pasivo o activo en la comisión de un delito, pudieran resultar dañados o perjudicados sin posibilidad de que tengan un resarcimiento satisfactorio. 
13. La incorporación de las propuestas de este trabajo de investigación en la Ley General de Víctimas, pudieran armonizarse con las legislaciones estatales que cuenten con leyes respectivas y las que no, con su incorporación en la legislación penal.

14. Nuestro país estaría a la vanguardia en materia de protección y resarcimiento a los tipos de víctimas que se proponen en la presente. 


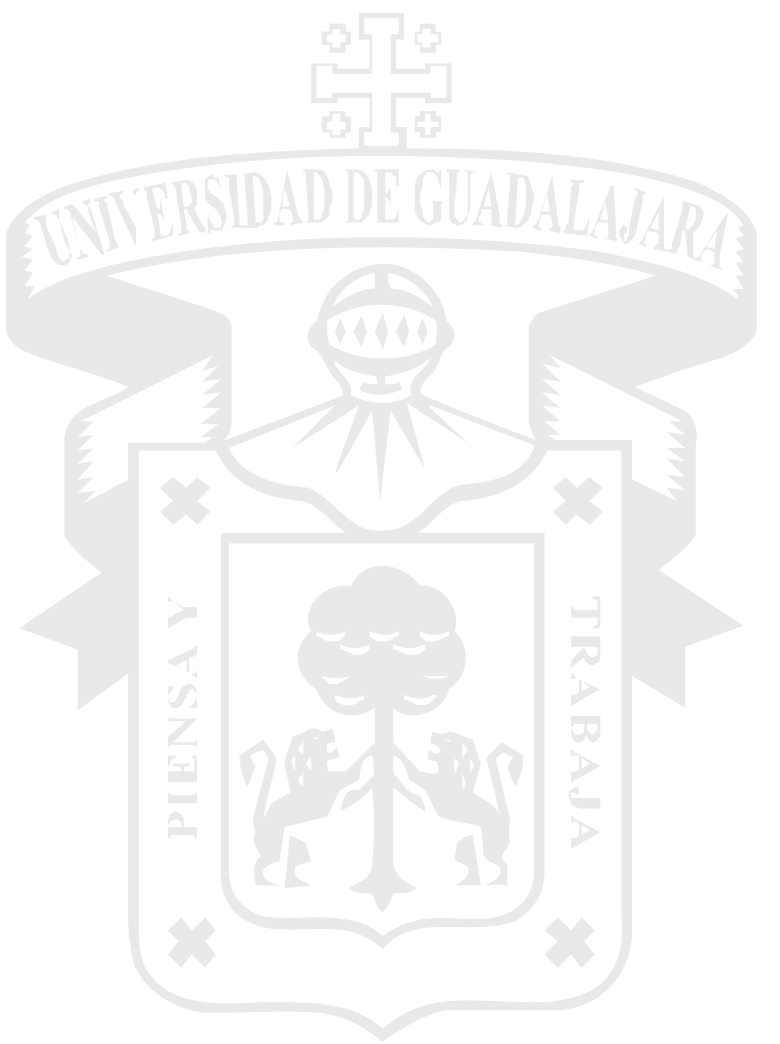

